\title{
Saberes de Mujeres y Varones Triquis Respecto de la Crianza de sus Hijos: Cambios y Continuidades Generacionales
}

\author{
Knowledge of Women and Males Triquis \\ Regarding the Breeding of its Children: \\ Changes and Generation Continuities
}

1 Profesora del Departamento de Historia y Filosofía de la Medicina. Facultad de Medicina. Universidad Nacional Autónoma de México zuanilda@hotmail.com
RESUMEN En este artículo se describen los saberes que mujeres y varones triquis tienen respecto de la crianza de sus hijos así como de otros procesos de salud reproductiva, con el objetivo de analizar las transformaciones y continuidades que sobre estos aspectos se observan en dos generaciones de familias triquis, localizada la primera en su lugar de origen (Copala, Oaxaca) y en la ciudad de México la segunda. Nuestra intención es dar cuenta de la asignación de roles diferenciales entre los géneros, sus relaciones desiguales, el ejercicio del poder entre ellos y su influencia en las decisiones ante un problema de salud y la resolución del mismo. Se describirán las representaciones y prácticas sobre lactancia, destete, ablactación, alimentación actual, higiene personal y ritual, contacto físico y las manifestaciones de afecto, así como sobre las prácticas preventivas que se realizan con los hijos pequeños como parte de los saberes que estos grupos domésticos tienen para proteger y cuidar a su descendencia en busca de la supervivencia del grupo.

PALABRAS CLAVE Crianza; Identidad de Género; Relaciones Familiares; Valores Sociales.

\begin{abstract}
In this article the knowledge are described that women and males triquis have regarding the breeding of its children as of other processes of reproductive health, with the objective to analyze the transformations and continuities that on these aspects are observed in two generations of families triquis located the first one in its place of origin (Copala, Oaxaca) and the second in Mexico City. Our intention is to give account of the assignation of different roles between genders, the unequal relations, the exercise of power and its influence in the decisions before a health problem and the solution of it. We will make a description of the representations and practices in the lactation, the ablactation, the weaning, the actual alimentation, the personal and ritual hygiene, the physical contact and the love manifestation as well as the preventive practices which are realized with the smaller sons as part of the knowledge that these domestic groups have to protect and take care of their descent searching the groups survivorship.
\end{abstract}

KEY WORDS Breeding; Gender Identity; Family Relations; Social Values. 


\section{INTRODUCCIÓN}

El objetivo de este artículo es describir los saberes que tienen mujeres y varones triquis acerca de la crianza de sus hijos, así como analizar determinadas relaciones que se desarrollan en términos de pareja, observar sus modificaciones y/o continuidades que se llevan a cabo en términos generacionales entre los miembros de este grupo étnico mexicano. Por lo tanto describiremos las relaciones de género a través de grupos domésticos pertenecientes a dos generaciones para analizar la asignación y distribución de roles, las condiciones de desigualdad, el ejercicio del poder en la toma de decisiones ante diversos procesos de salud/enfermedad/atención, así como determinadas relaciones a nivel de pareja.

La reproducción humana constituye una etapa de la vida que requiere de cuidados y precauciones especiales para su buen desarrollo; es uno de los acontecimientos del ciclo vital que mayor importancia tiene para el hombre y su grupo social y que ha dado lugar al desarrollo de representaciones y prácticas sociales específicas. Los patrones de crianza ocupan un lugar central en los diferentes grupos sociales y tienen como objetivo asegurar la reproducción biosocial de dichos grupos, expresado en los saberes construidos y utilizados por los grupos domésticos (1).

Nuestra descripción de estos procesos de salud reproductiva tomarán a la familia como unidad de descripción y análisis, ya que es la institución donde inicialmente se constituyen los sujetos sociales y sus saberes, y a través de la cual podemos captar las representaciones y prácticas sociales organizadas en torno a la reproducción biosocial y que ponen en juego los diferentes comportamientos de los dos géneros involucrados en dicha reproducción. Desde las ciencias sociales en general y la antropología médica en particular existe una tradición disciplinar que ha estudiado a la familia en relación con el proceso s/e/a, reconociéndola como la unidad en donde es posible llevar a cabo la descripción y análisis de dichos procesos así como donde se desarrollan y aplican los saberes respecto del proceso s/e/a (2).

Los estudios de género han mostrado especial interés en este proceso ya que a través del mismo critican las desventajas, inequidad, desprotección y mayor riesgo al que está expuesta la mujer respecto de su rol reproductivo en el que ha sido encasillada, tratando de sustentar una posición de opresión y subordinación de la mujer apegado a su papel de reproductora $(3,4)$.

En las comunidades indígenas de México las normas de interacción entre los géneros y las generaciones, los espacios y roles de cada uno de ellos, así como los derechos y decisiones respecto a la salud son diferenciales e inequitativos (5). Por lo que consideramos que el proceso reproductivo nos permite un espacio de análisis de la manera en que las asimetrías, desigualdades, diferencias y apoyos se construyen a lo largo de las diferentes etapas de la vida, de las formas en que los individuos se relacionan y construyen una serie de estrategias sociales y familiares en torno al cuidado y atención de sus hijos.

\section{ALGUNOS ASPECTOS METODOLÓGICOS Y CONTEXTUALES}

Antes de describir los procesos centrales de nuestro estudio vamos a presentar algunos datos contextuales respecto de los sujetos sociales con que trabajamos. Las mujeres y varones triquis estudiados pertenecen a cinco grupos domésticos migrantes a la ciudad de México y ubicados en La Merced, una de las zonas populares más importantes y céntricas de nuestra ciudad capital, con un tiempo de permanencia variable entre diez y quince años, así como una constante movilidad de ida y vuelta entre la ciudad de México y su región de origen.

Se entrevistaron a un total de dieciocho informantes, ocho varones y diez mujeres, con edades que fluctuaron entre 16 y 50 años, pertenecientes a dos generaciones. La información se obtuvo a través de trabajo etnográfico tanto en la región de origen como en el asentamiento urbano, buscando obtener no sólo sus representaciones sino observando también sus prácticas y apoyándonos para ello en mi propio trabajo médico/clínico y en el del centro de salud de la Secretaria de Salud que les da atención. Subrayo que la información se basa en observación participante y en entrevistas realizadas a los miembros de las respectivas parejas, y no sólo al 
representante de uno solo de los géneros, que como sabemos es la orientación que domina los estudios basados en la perspectiva de género. Si bien la mayoría de la información obtenida proviene de las mujeres, reiteramos la importancia de la información obtenida de los varones entrevistados. El trabajo de campo en Copala duró cuatro meses y en la ciudad de México fue de quince meses.

Las familias triquis entrevistadas son originarias de la cabecera municipal de San Juan Copala ubicada en la mixteca alta del estado de Oaxaca, una de las regiones más pobres de México, pobreza que se expresa en tasas de mortalidad general de su población muy por arriba de la registrada a nivel nacional: 8,21 por 1.000 habs. para Copala en contraste al 4,47 por 1.000 habs. nacional en el año 1999. La región se caracteriza por una alta incidencia de violencia que ocasiona la muerte de la mayoría de los varones en edad productiva, la muerte violenta ocupó la primera causa de mortalidad entre la población de San Juan Copala para el año 1999, con un 23,07\% del total de las muertes de ese año, siendo el grupo afectado el de varones entre los 15 y los 44 años. Esto también ha favorecido el desarrollo de una representación colectiva estigmatizante: los triquis son "rebeldes", "salvajes", "necios", así como de que su región es "insegura" en términos de violencia y en especial de homicidios.

San Juan Copala presenta desde hace varias décadas, al igual que la mayoría de las poblaciones mixtecas, uno de los índices más altos de migración a zonas urbanas del país, a regiones de agroindustria y agricultura de exportación en la frontera norte del territorio nacional, así como a Estados Unidos de Norteamérica y otros países del Norte del continente.

Los triquis entrevistados viven en el barrio de La Merced en un espacio de $1.500 \mathrm{~m}^{2}$, se localizan 48 viviendas con uno o dos cuartos de dos por tres metros cuadrados de extensión cada una. En cada vivienda viven entre siete y ocho personas. El predio cuenta con dos baños colectivos, una toma de agua a través de un hidrante público, luz eléctrica en todos los cuartos y drenaje conectado a la red pública.

Nuestros datos evidencian que mejoran las condiciones de vida de estas familias triquis al migrar desde zonas rurales de Oaxaca a la ciudad de México, y en particular mejora su ingreso económico, su escolaridad y su alimentación. Especialmente observamos una mayor cantidad de nutrientes en su dieta, lo cual se manifiesta en la disminución de las tasas de mortalidad en todos los grupos de edad, resaltando en función de nuestros objetivos, la disminución de la mortalidad infantil. Si bien en los aspectos sanitarios también se observan algunas mejorías, no obstante se mantienen condiciones de promiscuidad y hacinamiento. Hay además mayor disponibilidad y accesibilidad a los servicios de salud, lo que posibilita la atención y solución de sus problemas con mayor rapidez y eficacia que en Copala (6). Por lo cual su vida cotidiana en el medio urbano favorece mejores condiciones de salud.

Múltiples y diferentes son los cambios que estos grupos domésticos muestran entre sus generaciones asociados con su migración a la ciudad de México, a los cuales describiremos a continuación y especialmente referidos a la crianza de sus hijos.

\section{"UN PUEBLO SIN NIÑOS NO ES UN PUEBLO, ESTÁ MUERTO".}

Las familias triquis han reducido notoriamente en un par de generaciones el número de sus integrantes, y especialmente el número de hijos. Los migrantes de la primera generación pertenecen a familias con ocho a doce hijos, mientras los de la segunda generación tienen entre cuatro y cinco hijos. Al respecto es importante señalar que para los hombres y mujeres de este grupo étnico y en particular de estos grupos domésticos, los niños tienen un alto valor social. Según nuestras entrevistadas una familia sin hijos no tiene razón de ser, ya que la causa por la que un hombre y una mujer se unen es para lograr una familia. En ellos el concepto de familia se centra en la presencia de los hijos, pero esta necesidad no se limita a la familia sino que se amplía, se extiende a la presencia de niños en la comunidad y más aun a la presencia de nuevos triquis que prolonguen y mantengan a su grupo social. "Un pueblo sin niños está muerto, está triste, no tiene vida." 
Si bien la procreación de hijos es responsabilidad y tarea de hombres y mujeres, cada género desarrolla diferentes actividades, roles y funciones. En principio es en la mujer en quien se descarga la responsabilidad de lograr un embarazo de forma temprana y lo más pronto posible; si al año de haberse iniciado la vida sexual activa no han logrado gestación, la mujer puede ser maltratada, menospreciada e incluso devuelta a sus padres por no haber cumplido de forma satisfactoria la expectativa de cualquier matrimonio.

Es la suegra la primera en presionar a su hijo cuando su mujer no logra embarazarse rápidamente, incluso puede sugerir que el hijo busque otra mujer que logre proporcionarle descendencia, ya sea abandonando a la primera esposa o complementándola a través de la poliginia. Es importante señalar que en la segunda generación, residente en la ciudad de México, la influencia de la suegra disminuye sobre todo en el control del comportamiento de su nuera.

Las mujeres triquis han aprendido desde la infancia a través de las otras mujeres, que los hombres triquis lo que desean, piden y exigen a sus mujeres es que les den hijos. Por lo tanto todas las mujeres buscan embarazarse inmediatamente después de casarse, lo cual confirmará su capacidad reproductiva. Después del primer hijo, en la primera generación, se busca el mayor número de embarazos, mientras en la segunda generación se negocia dicho número entre los miembros de la pareja. Se negocia sobre todo la mayor separación entre uno y otro embarazo, así como la planificación del número de hijos que la pareja desea tener y que variará entre tres y cinco. Si bien las parejas de la segunda generación pueden llegar a pensar en tener seis $u$ ocho hijos, existe una diferencia notoria con la primera generación, ya que ésta no plantea ningún número sino que aceptan "todos los que Dios les mande", y que pueden ser uno o veinte. El número de hijos para la primera generación y para los que siguen residiendo en Copala no es una decisión de la pareja sino una decisión divina, por lo tanto no hay límite al número de hijos y se excluye la intervención para reducir su número.

Son las mujeres triquis las que primero adquieren patrones urbanos de composición familiar, concepciones que aparecen reforzadas constantemente por los medios masivos de comunicación, los servicios de atención biomédica, las escuelas y otras instituciones que van incidiendo en las concepciones y prácticas sobre el tamaño y dinámica de las familias.

Un aspecto importante en las representaciones de la segunda generación triqui, es que los hijos cuestan dinero; de tal manera que para poder proporcionarles una mejor calidad de vida, que incluye buena comida, ropa, calzado, escuela, juguetes y otros medios de diversión se requieren recursos económicos para satisfacerlos, por lo que entre menos hijos se tengan mayores serán las posibilidades de satisfacción. Esa concepción entra en contradicción con las representaciones de la primera generación para quienes los hijos significaban la seguridad de su vejez. Se espera el apoyo laboral y económico en el caso de los hijos varones en edad productiva, mientras que respecto de la hija mujer se espera el precio de la dote o un aporte económico que su familia recibe de la familia de su esposo al casarse la hija (a).

Es en función de estos saberes sobre el papel de los géneros, que la mayoría de los hombres y de las mujeres triquis desean que su primogénito sea un varón, ya que éste les garantizará su seguridad en la vejez. De nuestros datos surge que en los subsecuentes embarazos al parecer no existen preferencias por el sexo de los hijos, pueden ser hombres o mujeres, aunque lo ideal es que la familia cuente con hijos de ambos géneros, ya que el apoyo que cada uno de ellos proporciona será importante y diferencial. Las hijas mujeres constituyen la principal ayuda para la madre en las labores domésticas, que incluye el aseo de la vivienda, la elaboración de los alimentos, así como el cuidado de los hermanos menores. En el caso de los hijos varones serán la mano de obra que apoyará al padre en las labores productivas del campo, en las actividades comerciales y en la producción artesanal. Si bien en las representaciones sociales de los triquis existe una asignación de tareas y espacios diferenciales para cada género, no obstante en la práctica tanto hombres como mujeres pueden compartir determinadas actividades, aunque es más frecuente que sea la mujer quien apoye cuando es necesario el trabajo identificado con 
el rol masculino como pueden ser la siembra o la venta de su producción agrícola.

Las jóvenes mujeres de la nueva generación nos refieren representaciones acerca de los hijos, que son vistos como una limitante para realizar sus actividades productivas, que a fin de cuentas son las que les proporcionan una remuneración económica. Este esfuerzo se expresa a través del valor diferencial dado a cada género; y así el esfuerzo se experimentará con mayor valoración si se trata del primogénito y varón, mientras que si es una hija mujer y ocupa el tercer o quinto lugar por su nacimiento en la familia, el esfuerzo de su cuidado puede ser experimentado como una carga por la madre.

También observamos diferencias en las representaciones de las mujeres de la segunda generación respecto de la función y el deber ser de una buena madre triqui, la cual debe estar dedicada totalmente a sus hijos y construyendo su razón de ser mujer en su capacidad de ser madre, que con el tiempo se verá recompensada al crecer sus hijos y encontrar en ellos el apoyo y cuidado necesarios en su etapa de madurez y vejez. Pero estas jóvenes madres ya no están seguras de que sus hijos constituirán su seguridad posterior y por lo tanto se resisten a invertir tanto esfuerzo en el trabajo de criar a un mayor número de hijos que pueden no resultarles una buena inversión.

\section{CUIDADO Y ATENCIÓN DE LOS “NENES” (b).}

Por crianza me refiero a las actividades que el grupo doméstico y en especial la madre, desarrollan para atender el crecimiento de sus hijos menores de cinco años, y que constituyen cuidados indispensables para la supervivencia de los mismos. Dicho proceso de crianza incluye entre otras actividades lactancia, ablactación, alimentación actual, higiene, afecto, juegos, acciones preventivas biomédicas y tradicionales. La información obtenida sobre crianza la describiremos según el papel diferencial observado entre hombres y mujeres respecto de las dos generaciones ya señaladas con el objetivo de mostrar las diferencias por género y generación.

\section{LACTANCIA}

Todas las familias refieren que el alimento aceptado por excelencia para la alimentación de los pequeños es la leche materna que se forma de la comida que consume la madre, principalmente de aquellos alimentos que contienen maíz (tortilla y atoles), "porque el maíz es lo que forma el cuerpo y lo mantiene fuerte". Todas las mujeres de estos grupos amamantan a sus hijos; no hacerlo sería considerado como una falta de cumplimiento a su rol como madre y por lo tanto propiciaría ser cuestionada como mala madre, mala esposa y mala mujer.

Una de nuestras informantes nos refiere las dificultades que tuvo para amamantar a su hijo, así como los cuestionamientos hacia su rol de madre. Ella inició la lactancia de su hijo desde su nacimiento, pero tuvo dificultades para amamantarlo dado que uno de los pezones no estaba bien formado y le surgieron grietas que limitaron la lactancia debido al dolor. No obstante esta complicación, ella no suspendió el amamantamiento, porque sentía cuestionada su condición de mujer y madre al no poderle dar de comer a su hijo, situación reforzada por la actitud de su marido y su grupo doméstico. "Yo quería que el nene no se despertara para que no me pidiera de comer, porque en cuanto despertaba y lloraba, Francisco me lo traía y me decía dale, aunque sea del otro lado dale, pero a mí me dolía tanto la chichi (teta) mala porque estaba llena de leche y hasta me sangraba. Me lo pegaba, estaba mi pecho lleno de leche y sangre pero así lo agarraba el nene".

Recurrió a diferentes alternativas para que su pezón se curara y pudiera amamantar sin problema a su hijo. Primero acudió al centro de salud y luego al hospital, donde le dieron medicamentos e indicaciones generales para combatir la infección que se agregó, pero sólo tuvo una ligera mejoría. Se sentía desesperada porque no se aliviaba, y su mamá trajo a una curandera, quien la limpió y sahumó para combatir "esa mala fortuna" que les estaba sucediendo a ella y su "nene", ya que éste no comía y Iloraba constantemente dado que no podía amamantarlo. Su mamá y su esposo atribuyeron la causa de este percance a la no satisfacción de un antojo durante su embarazo, y por ello constantemente insistían en que 
recordara "que cosa se le había antojado mucho cuando esperaba al nene", para poder satisfacerlo y solucionar la complicación que se le presentaba. Recordó varias cosas que se le habían antojado y todas le fueron compradas, con lo cual la imposibilidad de amamantar se solucionó.

La lactancia es realizada por estas jóvenes a libre demanda y por un lapso de tiempo variable entre los 12 y 18 meses en la segunda generación y 3 a 4 años en la primera. No se guardan cuidados especiales durante el desarroIlo del amamantamiento como lo indica la biomedicina: la higiene del pezón, la expulsión del aire o la posición en que debe colocarse al lactante; en general estas madres hacen caso omiso de estas indicaciones aunque enfermeras y médicos del centro de salud o el hospital se los han referido frecuentemente, éstas no impactan sus prácticas. Lo que sí se reconoce y se vigila constantemente es el cuidado de no exponerse al "frío" (c) dado que, según sus concepciones, el "frío" reducirá la producción láctea en la madre y ocasionará dolor abdominal y diarrea en los hijos. Por lo cual las madres evitan ingerir alimentos considerados "fríos" o exponerse a cambios de temperatura al mojarse.

Otros aspectos vigilados en la lactancia es la colocación del zoyate (d) que propicia la mayor producción de leche y asegura así la saciedad del hambre en el menor, así como que la mujer no reciba sustos (e) ni corajes (f) que enfermen al niño al trasmitirse por la leche dichas emociones, por lo tanto su esposo como su familia deben procurar no disgustarla y cuidarla.

Entre la primera y segunda generación encontramos diferencias acerca de los conocimientos que ellas tienen para enfrentar este periodo. Las jóvenes son capacitadas por sus madres o suegras pertenecientes a la primera generación, les dan indicaciones sobre los cuidados relacionados con la dieta, la protección contra el frío, la forma de cargar y cuidar al nene, ellas vigilan que sus indicaciones sean Ilevadas a cabo para evitar complicaciones y gastos por enfermedad durante este periodo; las jóvenes madres reproducen las indicaciones pero en su mayoría no conocen las explicaciones. Los varones de ambas generaciones conocen estas indicaciones y consejos, pero dejan en manos de las mujeres mayores la vigilancia de los mismos.
Para hombres y mujeres de la segunda generación la lactancia artificial es mejor que la materna por ser la leche enlatada un producto de alto costo y contener elementos adicionales que socialmente son reconocidos como de alto valor nutritivo, como es el caso de las vitaminas y el hierro. Estas representaciones las han adquirido del contacto con otras madres urbanas, con los medios de comunicación y con el personal de salud que así se los manifiestan. Es en los varones en quienes dominan estas representaciones acerca de la leche enlatada, al ser ellos quienes mantienen mayor contacto con individuos externos a su grupo étnico; ellos ejercen presión sobre sus mujeres para que complementen la alimentación de los pequeños con productos comercializados y enriquecidos, incluso desde el momento del nacimiento. Los padres compran latas de leche en polvo en las farmacias indicando a sus mujeres dársela a los hijos por ser mejor alimento, pero esta alimentación no se puede mantener por largos periodos, dado el costo del producto lácteo, y por ello en la práctica lo que predomina y se mantiene es la lactancia materna.

\section{DESTETE, ABLACTACIÓN Y DIETA}

El período en que se extiende la lactancia por lo general es largo, y está condicionado por diversos factores, entre ellos la ventaja de ser la leche materna un alimento gratuito en comparación con el costo que representan los alimentos comerciales "buenos pero caros", así como ser un alimento fácil de proporcionar aun en la calle donde la madre realiza su actividad productiva vendiendo sus productos.

Para la primera generación el destete o suspensión de la lactancia se da sin una planificación específica, generalmente al sobrevenir un nuevo embarazo, por lo que variará entre los 2, 3 o 4 años. Ellas prefieren darles a sus hijos durante ese tiempo leche materna, para no invertir tiempo ni dinero en otro tipo de alimento. En la nueva generación la lactancia se puede suspender espontáneamente por decisión de la madre y/o indicación del personal de salud, pero también consideran que una mujer embarazada no debe proporcionarle a su hijo leche materna, ya que esa leche concentra el calor de un nuevo 
embarazo, es leche asignada a otro nuevo hijo y por lo tanto enfermará al niño mayor, de tal manera que el niño se enfermará de chipilez (g) mostrándose irritable, llorón, sin apetito y perdiendo peso.

El ingreso de otros alimentos además de la leche en la dieta de los pequeños, también presenta variaciones y diferencias a nivel generacional y de género. Para varones y mujeres de la primera generación, durante el primer año de edad, el nene debe alimentarse solamente con leche materna; en todo caso se le proporcionarán probaditas de algunos alimentos (tortilla, frijol, atole) o bien alimentos masticados por la madre y que le dará en pequeñas cantidades, evitando alimentos grasosos o picosos. No se preparan alimentos especiales para ellos porque los alimentos extraños pueden ocasionar enfermedades gastrointestinales dada la mayor vulnerabilidad de los niños pequeños.

Para la segunda generación y en especial para los varones, se presenta la representación de que a un niño pequeño hay que proporcionarle alimentos "buenos" que contengan productos que los hagan crecer, ser fuertes y estar sanos. Dichos alimentos no son los que integran la dieta diaria, sino aquellos alimentos caros que se anuncian en los medios de comunicación o que el personal de salud recomienda. Por esta razón en algunas familias el esposo le da indicaciones precisas a su mujer, e incluso le deja dinero especialmente para que le compre y proporcione a su pequeño hijo los alimentos necesarios para alimentarlo bien y que así crezca sano y fuerte.

En la mayoría de los casos estos alimentos son productos comerciales promocionados como de alto contenido alimentario: "Danonino, Gerber, jugos, yogurt"; así como vitaminas comerciales, productos en quienes los informantes depositan expectativas positivas respecto de su efecto en la buena salud y crecimiento de los niños. Si bien también se les da a los hijos huevo, carne y fruta que proporcionan los nutrientes necesarios según el discurso biomédico, estos alimentos no son parte de dieta familiar cotidiana.

\section{HIGIENE PERSONAL Y RITUAL}

Acerca de los saberes que estos grupos tienen respecto de la higiene de sus hijos pequeños encontramos diferencias entre la generación joven y la primera generación, ya que en los miembros de esta última no existe como importante la representación de mantener limpio al pequeño. A partir de este reconocimiento revisaré varios aspectos que permiten observar ciertos cambios generacionales.

Inmediatamente luego del parto, el recién nacido es limpiado con un poco de aceite, se lo viste y envuelve en cobijas, pero luego pueden pasar entre 10 y 12 horas antes de que se revise si se encuentra mojado o sucio para cambiarlo. Entre los niños mayores de tres años el baño y cambio de ropa se realiza con poca frecuencia, en promedio cada 3 o 4 días, ya que no se considera necesaria la higiene personal, pues no se le asigna una función o necesidad especifica.

Si bien la higiene, tal como la concibe la biomedicina, no aparece significativa para nuestros informantes, en cambio tiene un papel decisivo la protección respecto del "frío", ya que se teme que al recibir "frío" el niño se enferme. La parte más cuidada del cuerpo es el ombligo, considerado como un orificio que conecta directamente con el cordón umbilical, y que posibilita la entrada del "frío" al abdomen lo cual puede ocasionar dolor abdominal, diarrea y hasta la muerte del pequeño. La relación frío/caliente se observa también en ciertas prácticas realizadas durante el proceso de cicatrización del muñón umbilical: se colocan sobre él elementos calientes como cera, cebo o un machete caliente al rojo vivo en la lumbre, lo que ocasionará que el muñón se seque más rápidamente, se caiga y así evitar el riesgo de putrefacción.

Es decir que sobre todo en la primera generación la relación frío/caliente tiene mayor significación que la higiene personal y grupal, y esto podemos observarlo en forma paradigmática en el baño de temascal (h) que especialmente la primera generación aplica a sus hijos recién nacidos, y que no tiene como objetivo la limpieza física del pequeño sino el calor que ayudará a su cuerpo a recibir fuerza, "porque el calor recose el cuerpo", le proporciona fuerza y en consecuencia previene enfermedades, proporciona elementos para crecer, caminar rápido, ser fuertes y sanos. Esta práctica realizada en forma constante busca construir un hábito benéfico para la salud del infante. 
Los jóvenes padres de la segunda generación manejan representaciones respecto a la higiene personal de los niños que pasan por el saber biomédico, aprendido a través de diversas vías ya señaladas. Dichas representaciones incluyen el uso higiénico del baño frecuente (cada tercer día o diario), el cambio de ropa y el cuidado personal, no solo por el beneficio explícito que hace manifiesto el discurso biomédico, que busca la prevención de enfermedades y en consecuencia la salud, sino sobre todo por la apariencia de mantener a sus hijos limpios y "bonitos" como la gente de la ciudad.

Si bien estos jóvenes conocen las concepciones acerca del frío como causa de enfermedad de sus hijos y hermanos, las ponen en duda. Más aún, estos padres ya no realizan el baño de temascal por no contar con dicho recurso en la ciudad, pero tampoco lo sustituyen con otra práctica alternativa. Al respecto hemos observado que cuando regresan a visitar su localidad de origen tampoco utilizan el temascal, ya que sus hijos no están acostumbrados y se asustan si se intenta este tipo de baño.

\section{CONTACTO FÍSICO Y MANIFESTACIONES DE AFECTO}

El contacto físico que tienen los integrantes de estos grupos domésticos con sus niños pequeños debe ser resaltado, ya que las madres mantienen cerca a sus "nenes" durante todo el día, cargándolos en el rebozo (i) mientras realizan sus labores cotidianas. Sólo por lapsos cortos de tiempo los dejan recostados en la hamaca (j) o sobre el petate $(k)$ y durante la noche duermen con ellos a su lado, es decir que la madre mantiene con el niño un contacto físico constante. Existe una representación generalizada de evitar en lo posible dejar solo a un pequeño, porque los espíritus de las cosas, incluyendo el espíritu de la casa, puede jugar con él y "asustarlo".

Todos los miembros del grupo doméstico tratan al niño pequeño con expresiones de afecto; se le habla en lengua triqui y con palabras cariñosas, siendo muy notoria la diferencia entre la interacción con los pequeños y la que se tiene con los niños mayores y con los adultos. Con estos no se tienen manifestaciones cariñosas ni se emplean palabras afectuosas en la interacción cotidiana de estas familias. Conforme el hijo va creciendo la relación y el contacto familiar va cambiando, pasando a partir de los tres años a ser atendidos y cuidados por sus hermanos o hermanas mayores en vez de por su madre. La atención y cuidado especial que se les tenía se va reduciendo, se los deja solos, no se pone atención en su higiene ni en su alimentación, pasando a ser un miembro más del grupo. Quizá en el caso del primogénito varón la atención especial por parte de la madre se prolongará un poco más.

El cambio en la atención y cuidado materno hacia el hijo se produce como consecuencia de la presencia de un nuevo embarazo y un nuevo pequeño al cual deben cuidar, por lo cual se transfiere el cuidado del hijo anterior a los hermanos.

\section{MEDIDAS DE PROTECCIÓN Y PREVENCIÓN}

Un aspecto muy relevante en el cuidado de los pequeños es el que se realiza de forma ritual con o sin la intervención de los curadores tradicionales. Ya mencionamos la utilización del baño de temascal para fortalecer a través del calor el cuerpo del niño. Existen otras prácticas preventivas o propiciatorias del buen estado de salud, crecimiento y fortaleza del niño, ya que se maneja la representación social de que "el nene es débil, su cuerpo necesita calor para fortalecerse, necesita cuidados para poder crecer y sobrevivir". Esta protección puede obtenerse por la intervención y práctica de la curandera tradicional, quien a través de limpias, ofrendas y rezos solicita de forma regular a sus santos que el nene esté sano y no se enferme. Estas prácticas las realizan de forma regular las familias de la primera generación, cotidianamente, una vez por semana o quincenalmente, durante la visita al tianguis (I) o a la cabecera municipal. Durante las actividades vespertinas o de fin de semana estas familias acuden a solicitar el servicio de las curanderas quienes realizan prácticas adivinatorias y propiciatorias para la salud del niño. En cambio, para la segunda generación estas prácticas no son necesarias, incluso las cuestionan, aunque sin embargo las realizan bajo la indicación o presión de sus madres y suegras. Los varones no intervienen 
indicando o sancionando estas prácticas, sin embargo al no desacreditarlas indirectamente las autorizan y en ocasiones por indicaciones de sus madres se las ordenan a sus esposas.

La otra protección o tratamiento inicial en caso de que se considere al nene débil o enfermizo, inapetente, irritable o que no crece, será una práctica conocida como "Evangelio", la cual consiste en seleccionar a un padrino que es considerado con buena suerte y/o de prestigio en la comunidad. A través de su intervención trasmitirá esa suerte a su pequeño ahijado. Por medios adivinatorios $(\mathrm{m})$ se selecciona al padrino, idealmente persona de respeto y del mismo grupo étnico, aunque las nuevas generaciones seleccionan personas externas al grupo y con recursos económicos. Esta práctica busca trasmitirle al nene la suerte del adulto y con ello ayudarlo a crecer y estar sano. Si no da resultado, se puede seleccionar otro padrino, de tal forma que pueden ser muchos los padrinos de evangelio que tenga un pequeño. En ocasiones la limitante de este ritual es el gasto económico, ya que los padres del pequeño deben ofrecerle al padrino y su familia, comida y bebida. El ritual se realiza en la iglesia católica sin la intervención del sacerdote, de tal manera que la familia del niño, el niño y el padrino acuden frente a los santos, el padrino solicita buena suerte, fuerza y salud para el niño, realiza una limpia con flores, agua, velas y monedas, tocando al santo y luego al pequeño para trasmitirle su poder. Luego los familiares comparten la bebida y la comida para sellar el compadrazgo.

También el bautismo es reconocido como un ritual que beneficia el niño, por ser el padrino un recurso de apoyo y buena suerte para el pequeño, además de recibir durante el bautismo la protección divina. Tanto el evangelio como el bautizo son prácticas que realizan los grupos domésticos de ambas generaciones, compartiendo algunas representaciones acerca de ellas, aunque en quienes encontramos los datos y usos más detallados es en las mujeres de la primera generación. Debemos consignar que quien autoriza la selección del padrino y el gasto que implica la realización de estos rituales es el padre en ambas generaciones, por lo cual se espera su regreso de las temporadas migratorias o que envíe el dinero suficiente para llevar acabo la ceremonia. Por lo tanto los padrinos como las personas que sufragan los rituales pertenecen al género masculino.

Respecto de las prácticas preventivas biomédicas, estas familias aceptan sin rechazo la aplicación de vacunas a sus hijos. Si bien no saben por qué una vacuna puede prevenir de enfermedades a sus hijos, no obstante han aprendido por la experiencia que desde que los pequeños se vacunan hay enfermedades que no se presentan o su cuadro clínico es menos grave, y por ello ambos padres aceptan y buscan que sus hijos sean vacunados. Son los varones de la segunda generación quienes indican a sus esposas que estén pendientes que se realice la vacunación.

La vigilancia del crecimiento y desarrollo de los pequeños así como el control mensual de éste en la consulta médica no están integrados en los saberes de crianza de estas madres y padres. Si bien las jóvenes de la segunda generación acuden al centro de salud para que pesen y midan a sus pequeños, lo que buscan es que la enfermera les confirme que "su nene está gordo" y así se lo expresan a sus esposos generándoles orgullo, pero no reconocen ni ponen atención en otros parámetros del desarrollo psicomotor infantil. Al médico se acude en caso de enfermedad, no se le asigna un rol preventivo. Cuando el padre se encuentra en la ciudad suele acompañar a la madre a la consulta médica, es él quien interactúa con el médico y funciona como intérprete de la madre, aunque ella hable bien el español.

\section{RELACIONES DE GÉNERO Y PROCESOS DE SALUD REPRODUCTIVA: ALGUNAS REFLEXIONES}

A partir de la información obtenida es posible proponer algunas conclusiones respecto de las características de estas familias y la crianza en términos de relaciones de género.

Entre los aspectos más importantes, observamos el deseo de estas parejas de tener hijos, que se manifiesta de manera diferencial entre varones y mujeres. Es el varón quien presiona y exige a su mujer que le proporcione hijos, incluso puede recurrir a la poliginia para obtenerlos, lo que genera entre algunas parejas conflictos 
importantes. Los reclamos del varón por la falta de hijos se justifican ante el incumplimiento del rol social asignado a la mujer y la oportunidad también legitima en su grupo social, la búsqueda de descendencia con otras mujeres fuera del núcleo familiar e incluso de la adquisición de una segunda esposa. Esta actitud se esta modificando parcialmente entre algunas parejas jóvenes urbanas que realizan una negociación para decidir si se tienen o no más hijos, la joven mujer triqui busca limitar su fertilidad a través del uso de métodos anticonceptivos diversos pero sigue siendo vigilada y cuestionada por el varón, quien en la mayoría de los casos se niega a autorizar su uso, sobre todo cuando requieran la exploración ginecológica o se trate de un método definitivo. El deseo de tener hijos se constituye en un elemento de tensión al interior de las parejas que pone en evidencia relaciones intergenéricas de poder, pero también nos permite observar el poder ejercido por la generación al interior del mismo género, ejemplo de ello es la autoridad e influencia de la suegra en este conflicto. La tensión y el conflicto también pasan por la necesidad actual de las mujeres de realizar otras actividades fuera del núcleo doméstico, el desempeño de diferentes roles y la búsqueda de mejores condiciones de vida.

Debemos resaltar que el valor social asignado a los hijos ha sufrido importantes cambios ya que en la primera generación domina la representación de que los hijos constituyen una forma de seguridad social, una red de apoyo para la vejez tejida a través del tiempo por los padres y que debe ser recompensada con reciprocidad de los hijos. Mientras que para la nueva generación los hijos implican dedicar tiempo y esfuerzos económicos que en ocasiones pueden limitar las expectativas personales de sus padres. En ambas generaciones se sigue invirtiendo más en el varón porque se sigue pensando que él será quien apoyará más a sus padres, mientras que las mujeres son consideradas como una pérdida dado que al casarse y depender de su marido, ya no tiene obligaciones de este tipo con su familia de origen.

Respecto de los saberes de hombres y mujeres acerca de la crianza de sus pequeños lo que observamos es la asignación comunitaria y familiar de la responsabilidad de dicho cuidado a la mujer, son ellas a quienes se responsabiliza, incluso a quienes se les culpa cuando el descuido condiciona daño o enfermedad. Esta tarea se aprende entre mujeres, y durante este proceso de capacitación se trasmiten representaciones y prácticas que no sólo sirven para pensar y actuar sino para asegurar la continuidad cultural del grupo. Este saber es recibido de la primera generación por los nuevas madres, pero frecuentemente es cuestionado, desacreditado o no se lleva a cabo en la forma indicada por las mujeres de la primera generación, ya que estas jóvenes han adquirido representaciones y prácticas diferentes a través de su contacto con actores sociales urbanos, saberes que mezclan y sintetizan con el saber de su grupo respecto de la crianza, estableciendo una nueva forma de llevar a cabo los cuidados, vigilancia y atención de sus hijos. Las mujeres jóvenes ponen en duda lo que sus madres dicen, aunque sin embargo reproducen parcialmente muchas de sus prácticas, ya que dada su inexperiencia utilizan el saber de sus madres ante el riesgo de complicaciones en la salud de sus hijos pequeños, ya que los consideran vulnerables y débiles.

El cuidado infantil tienen como actora principal a la mujer, ellas poseen un conocimiento sobre la crianza que surge de la experiencia propia o de otras mujeres cercanas a su grupo doméstico, así como del contacto con los curadores populares o alopáticos.

Hay que resaltar la importancia que tiene la mujer en la atención al proceso s/e/a, ya que sobre ella recae el peso de cuidar y prevenir los padecimientos, pero pese a ello la mujer tiene un lugar subalterno respecto del varón tanto al interior del grupo doméstico como de la comunidad, lo cual podemos observar en distintos espacios, y especialmente en los espacios dedicados a servicios de salud.

Si bien, los varones están menos involucrados en el proceso de crianza por su menor permanencia en el ámbito doméstico y consideran esta labor esencialmente femenina, ellos juegan un papel importante en la interacción lúdica con sus pequeños hijos, sobre todo en el caso de los jóvenes padres quienes refieren representaciones acerca de la necesidad de darles afecto y juego a los pequeños para un mejor crecimiento. Pero son ellos quienes ejercen la autoridad de decidir la administración de leche artificial, 
alimentos enriquecidos y/o la elección del padrino de evangelio que protegerá al menor. Aun en la lejanía durante su migración en la frontera norte o en Estados Unidos de Norteamérica mandan indicaciones y autorizan decisiones tomadas por otros miembros de la familia.

Existen indiscutiblemente diferencias tanto en Copala como en México DF entre los géneros ya que en los grupos domésticos estudiados cada uno tiene asignado funciones específicas relacionadas con la supervivencia de dichos grupos, pero observamos que en el medio urbano se flexibilizan las normas comunitarias, lo cual genera la posibilidad de la nueva generación de involucrarse en roles incluso no asignados tradicionalmente a su género y a la vez tomar decisiones en su vida cotidiana, familiar y en la atención de sus hijos $(7,8)$. Lo que nos Ileva a concluir que los cambios observados en el proceso reproductivo están asociados a factores como el mayor grado de escolaridad, la incorporación de las mujeres al trabajo remunerado y a otras transformaciones de género que afecta la vida reproductiva de las mujeres y que se dan con mayor intensidad y frecuencia en los medios urbanos $(5,9)$.

Consideramos que las relaciones de género, así como determinados procesos operados en la situación de la mujer y especialmente los referidos a su instalación urbana y su incorporación al mercado laboral han repercutido sobre la salud de la propia mujer y de sus hijos (10), y que si bien estos aspectos han sido tomados en cuenta en México especialmente por las políticas de planificación familiar (11), han sido también ignorados y desvinculados de los programas y acciones específicas para la atención y prevención de la salud infantil, por lo que nosotros pretendemos enfatizarlos en este trabajo.

Para concluir debemos recordar que al nacer en sociedades diferenciadas por clase, etnia y género, los individuos ocupan posiciones asociadas a las categorías de mujer, varón, indígena, mestizo $(3,10,12,13)$. También heredan formas de entendimiento y con ello, los atributos asociados a su condición social. Si bien las relaciones de género están presentes en todos los aspectos descriptos en nuestro trabajo; y la perspectiva de género ha sido importante para elaborar nuestro marco analítico $(14,15,16)$, debemos sin embargo señalar que dicha perspectiva suele proponer una concepción fragmentada de la realidad ya que sólo tiende a incluir la información procedente de un solo género, casi siempre el femenino, para procesos respecto de los cuales es indispensable incluir las representaciones y prácticas de ambos géneros para así evidenciar y poder explicar el significado y sentido de las representaciones y practicas utilizadas por ambos géneros, como espero haberlo demostrado en este trabajo.

\section{NOTAS FINALES}

a. Por las mujeres triquis se paga una cantidad de dinero en efectivo al casarse, lo que se conoce como precio de la novia.

b. Se le da el nombre de "nene" entre los triquis a los niños pequeños menores de 4 o 5 años, es un término de afecto. c. La polaridad frío/caliente es un sistema taxonómico de las cualidades de cosas, personas y procesos; dicho sistema de clasificación es común en Latinoamérica y no se reduce a la relación con la temperatura ni en términos ambientales. Constituye uno de los elementos culturales de Mesoamérica y no funciona según la dinámica de la medicina hipocrática. 
d. Faja tejida con palma y estambre que sujeta la falda larga y que se colocan las mujeres en la cintura durante el puerperio.

e. El Susto o Espanto, síndrome cultural que surge a consecuencia de impresión súbita que ocasiona la pérdida de una entidad anímica y desencadena gran variedad de sintomatología; incluso puede ser grave o mortal.

f. Coraje se asocia al enojo que surge por diversas causas, entre ellas los problemas familiares. Ocasiona la producción de sustancias nocivas en el cuerpo de la madre que pueden ser trasmitidas al nene.

g. Enfermedad tradicional que se adquiere por el calor que, según las creencias populares, se produce en el cuerpo de la madre durante la gestación y se transmite a los niños pequeños ocasionando irritabilidad, decaimiento, diarrea, adelgazamiento, entre otros datos clínicos.

h. Baño de vapor de origen prehispánico, ubicado en el patio de la vivienda, elaborado con adobe y piedra, con una hornilla posterior de leña donde se calientan piedras a las cuales se les arroja agua con plantas medicinales que ocasionará la vaporización en el interior.

i. Rebozo: lienzo o manta con que las mujeres triquis cargan a sus hijos en su espalda.

j. Hamaca es un mueble colgante elaborado de diferentes textiles o bien acondicionado con el rebozo de la madre, se coloca entre dos postes y permite acostar al niño cerca de ella.

k. Tapete tejido de palma que se coloca en el suelo y sirve de cama.

I. Tianguis es un mercado ambulante que se ubica en diferentes poblaciones algunos días de la semana, donde se intercambian mercancías y servicios.

$\mathrm{m}$. Existen diferentes métodos adivinatorios en la comunidad, a través de lectura de cartas, de la vela, el copal, medida del brazo, sueños, etc.

\section{REFERENCIAS BIBLIOGRÁFICAS}

1. Jordan, B. Birth in four cultures: A crosscultural investigation of childbirth in Yucatan, Holland, Sweden, and the United States. Prospect Heights, Illinois: Waveland Press; 1993.

2. Menéndez EL. Familia, participación social y proceso salud/enfermedad/atención. Acotaciones desde las perspectivas de la antropología médica. En: Mercado FJ, et al., coordinadores. Familia, Salud y Sociedad. Experiencias de investigación en México. México: Universidad de Guadalajara, IISP, CIESAS; 1993. p. 130-162.
3. González Montes S. Hacia una antropología de las relaciones de género. En: González Montes S, coordinadora. Mujeres y relaciones de género en la Antropología Latinoamericana. México: El Colegio de México; 1997. p. 17-52.

4. Ojeda N. Género, familia y conceptualización de la salud reproductiva en México. México: El Colegio de la Frontera Norte; 1999. p. 263-300.

5. Freyermuth G. Invisibles y transgresoras, migración y salud reproductiva en los altos de Chiapas. 
En: Barrera D, Oemichen C, editoras. Migración y relaciones de género en México. México: GIMTRAP, UNAM/IIA; 2000. p. 203-228.

6. Mendoza GZ. De la casa del nene al árbol de las placentas. Proceso reproductivo, saberes y transformación cultural entre los triquis de Copala en la Merced. [Tesis Doctoral] México: CIESAS; 2004.

7. Langer A, Lozano R. Condición de la mujer y salud. En: Figueroa JG, compilador. La condición de la mujer en el espacio de la salud. México: El colegio de México; 1998. p. 33-82.

8. Bronfman M, Gómez Dantés H. La condición de la mujer y la salud infantil. En: Figueroa JG, compilador. La condición de la mujer en el espacio de la salud. México: El colegio de México; 1998. p. 89-125.

9. Stern C. El papel del trabajo materno en la salud infantil. Contribuciones al debate desde las ciencias sociales. México: The Population Council, El Colegio de México; 1996. p. 21-36.

10. Dean K. Self-care components of lifestyles the importance of gender, attitudes and the social situation. Social Science and Medicine. 1989;29(2):137-152.
11. Figueroa Perea JA. Aproximación al estudio de los derechos reproductivos. México: El Colegio de México; 1995. vol 8.

12. Mummert G. Mujeres de migrantes y mujeres migrantes de Michoacán. Nuevos papeles para los que se quedan y para los que se van. En: Calvo T, López Castro G, coordinadores. Movimientos de población en el occidente de México. Zamora: Colegio de Michoacán, CEMCA; 1998. p. 281-297.

13. González Chévez L. El pulso de la sobrevivencia. Estrategias de atención para la salud en un colectivo de mujeres del subproletariado urbano. [Tesis doctoral en Ciencias sociales y Salud] Barcelona: Universidad de Barcelona; 1993. p. 95-123.

14. Rubin G. El tráfico de mujeres: notas sobre la economía política del sexo. Nueva Antropología. 1986;8(30):95-145.

15. Lamas M. El género. La construcción cultural de la diferencia sexual. México: Miguel Ángel Porrúa, PUEG-UNAM; 1996.

16. Elu M, Leñero L. De carne y hueso; estudios sociales sobre género y reproducción. México: IMES; 1992. 